УДК 811.111'373

ББК 72.5

DOI: https://doi.org/10.17308/lic.2021.1/3245

\title{
БИГ МАК, ИЛИ ТРАЕКТОРИЯ ОДНОГО АНГЛИЦИЗМА В СОВРЕМЕННОЙ ПРЕССЕ
}

\author{
Е. А. Проценко \\ Воронежский институт МВД России
}

\section{BIG MAC OR A PATHWAY OF ONE ANGLICISM IN MODERN PRESS}

\author{
E. A. Protsenko \\ Voronezh Institute of the Ministry of the Interior of Russia
}

\begin{abstract}
Аннотация: статья посвящена проблеме использования лексики иноязычного происхождения в современной российской прессе. Актуальность данной темы подтверждается многочисленными работами как отечественных, так и зарубежных исследователей. На сегодняшний день СМИмогут рассматриваться как один из основных каналов проникновения англииизмов. Научная новизна исследования заключается 8 рассмотрении заимствования не как результата, а как актуального на сегодняшний день процесса проникновения иноязычной лексики. В иентре внимания автора оказывается лексика, перекодированная с английского языка, но еще не вошедшая в лексическую систему русского языка. Межъязыковое перекодирование рассматривается в статье как сложный процесс, который включает несколько этапов освоения иноязычного слова. Цель статьи - проследить начальную стадию вхождения иноязычного слова, обращая особое внимание на его графическое оформление и грамматические характеристики. В статье представлень результаты анализа контекстов употребления лексемы «биг» в российских газетах, начиная с начала ХХІ в., по базе данных Национального корпуса русского языка. В ходе исследования был проведен комплексный качественно-количественный анализ перекодированной лексики; применялись как общенаучные, статистические, так и собственно лингвистические методы. В результате была выявлена спеицфика графического представления анализируемой лексики, ее грамматические характеристики, наиболее частотные словосочетания, а также некоторые стилистические особенности употребления 8 российской прессе. Результаты исследования показали, что для начальной стадии проникновения иноязычной лексики характерны смена графической основы, вариативность написания, а также изменение ряда грамматических характеристик. При этом лексическое значение перекодированной единицы практически не изменяется, копируя язык источника заимствования. Автор отмечает также некоторые стилистические особенности употребления перекодированной лексики в газетном жанре.

Ключевые слова: межъязыковое перекодирование, англицизмы, ассимилячия иноязычной лексики, графическое оформление, грамматическое освоение, выразительное средство, язык СМИ.
\end{abstract}

\begin{abstract}
Russian press. The topic has been proven actual by a great number of both Russian and foreign researches. Nowadays the mass media can be regarded as one of the most important ways of anglicisms penetration. The scientific novelty of the study is as follows: lexical borrowing is regarded not as a result but as an ongoing process of foreign words acceptance. The author focuses her attention on lexical items recoded from English but not yet accepted into the lexical system of the Russian language. Cross-language recoding is represented in the article as a complex process including several stages of assimilating foreign words. The article aims to study the initial stage of foreign words acceptance paying special attention to its graphic representation and grammatical characteristics. The article presents the results of analyzing all the contexts of using the lexeme "big" in Russian newspapers issued since the beginning of the XXIst century and gathered in the National corpus of Russian language. A complex quantitative and qualitative analysis of recoded words has been provided within the present research. General scientific and statistic methods have been used as well as some linguistic methods of research. As a result, specific features of graphic representation of analyzed lexical items have been revealed, grammatical categories and the most common words combinations have been described as well as some stylistic peculiarities of its use in the Russian press. The results of the research
\end{abstract}

(C) Проценко Е. А., 2021

Контент доступен под лицензией Creative Commons Attribution 4.0 License.

The content is available under Creative Commons Attribution 4.0 License. 
have demonstrated that the initial stage of foreign words penetration can be characterized by modifying an alphabet system, variants of writing and changes of some grammatical categories. The lexical meaning of recoded words is still unchangeable imitating a source language. The author also notices some stylistic peculiarities of using recoded lexical items in newspapers.

Key words: cross-language recoding, anglicism, assimilating foreign words, graphic representation, grammatical assimilation, stylistic means, language of mass media.

\section{Введение}

XXI в. заявил о себе как век глобализации, цифровизации и инновационных технологий. Сегодня мы становимся свидетелями процессов и явлений, которые меняют нашу привычную жизнь, иногда коренным образом. В условиях, когда изменяется международная геополитическая и экономическая ситуация, пересматриваются государственные границы, трансформируются социально-политические контуры современного общества, не может оставаться неизменной и социолингвистическая ситуация. Для современной языковой ситуации характерно господство английского языка, которое воспринимается одними как поиск языка международного общения [1], другими - как языковая экспансия [2; 3]. Немаловажную роль в этом процессе играют современные средства массовой информации, которые не только транслируют определенные идеи, формируя массовое сознание, но и способствуют распространению моды на иностранные слова.

Независимо от оценки данного явления, нельзя игнорировать тот факт, что на сегодняшний день значительное число англо-американизмов используются практически во всех языках мира. В этой связи в разных странах проводятся как широкомасштабные [4], так и узконаправленные исследования англицизмов, их роли и функций в системе принимающего языка [5-8]. Актуальность данной темы подтверждается многочисленными работами как отечественных ([3; 7; 9; 10] и т. д.), так и зарубежных исследователей (например, [8; 11-13]).

Стоит отметить, что значительный объем лексики иноязычного происхождения, которая на сегодняшний день употребляется в русском языке, затрудняет ее классификацию. Понятие «заимствование», традиционно используемое в отечественной науке о языке, является достаточно широким и иногда толкуется разными исследователями по-разному: как общее обозначение лексики иноязычного происхождения или как уже освоенная в русском языке лексика [14].

В зарубежной лингвистике проблема использования лексики иноязычного происхождения рассматривается в последнее время с позиций взаимодействия языков как разных кодовых систем. В этой связи зарубежные исследователи отличают переключение кодов, как полную смену языка в рамках одного коммуникативного акта, от смешения кодов, для ко- торого характерно то или иное сочетание единиц разных языков [11; 12]. При этом смешение кодов обычно рассматривается как более общий термин [13]. Однако и при таком подходе одним из наиболее спорных вопросов остается понимание термина «заимствование» и его отличий от переключения или смешения кодов.

На основе комплексного интегративного подхода и исходя из понимания языка как языкового кода, нами было проведено различие между переключением языковых кодов и межъязыковым перекодированием, которое и послужило теоретической базой исследования [15]. Мы предлагаем понимать под межъязыковым перекодированием процесс кодирования единиц одного языка средствами и по правилам другого языкового кода. Данный подход позволяет нам отойти от традиционной теории заимствования и перенести акцент не на результат, а именно на процесс проникновения лексики иноязычного происхождения. Вслед за А. А. Кретовым мы считаем, что принцип «что есть в (академическом) словаpe, то есть в языке» существенно сокращает диапазон лексико-семантических исследований и обрекает на «лингвистическое несуществование» [16, с. 14] целые категории лексических единиц. К ним относятся, в частности, слова, образованные от иноязычных прототипов путем межъязыкового перекодирования, которое может быть представлено как сложный процесс, состоящий из нескольких этапов освоения иноязычного слова [17]. В данной статье мы сосредоточим свое внимание на начальной стадии, которая включает прежде всего графическое, фонетическое и грамматическое освоение иноязычного слова.

\section{Цель и задачи исследования}

Цель проведенного исследования - проследить начальную стадию вхождения иноязычного слова, обращая особое внимание на его графическое оформление и грамматические характеристики. В качестве примера мы выбрали лексему биг, которая достаточно активно используется в современной прессе, однако еще не вошла в состав русского языка. Газетный жанр выбран не случайно, ведь на сегодняшний день значительная доля иноязычной лексики употребляется именно в средствах массовой информации, которые можно рассматривать как один из основных каналов проникновения англицизмов [18; 19]. 
Для достижения поставленной цели необходимо решить следующие задачи: выявить все случаи использования анализируемой лексической единицы в современной прессе; проследить особенности графической репрезентации иноязычного слова; проанализировать грамматические характеристики перекодированной лексемы; сопоставить их с аналогичными характеристиками в языке-источнике; выявить стилистические особенности употребления анализируемой лексики в современной российской прессе.

\section{Материалы и методы исследования}

Исследование проводилось наматериале контекстов употребления лексемы биг, представленных в базе данных Национального корпуса русского языка за период с 2000 по 2019 г. Объектом исследования послужили более 1000 словоупотреблений, выявленных в текстах общим объемом около 500 документов.

В ходе исследования, наряду с общенаучными (синтез, анализ, дедукция) и статистическими методами, использовались методики компонентного и контекстуального анализа, а также комплексный качественно-количественный анализ лексики иноязычного происхождения.

Практическая значимость исследования заключается в возможности использования полученных результатов для выработки алгоритма установления факта или определения этапа заимствования лексики иноязычного происхождения.

\section{Результаты исследования}

По базе данных Национального корпуса русского языка [20] в газетном корпусе было выявлено более тысячи вхождений лексемы биг. Однако детальный анализ словоупотреблений показал, что в данном случае имеет место межъязыковая омонимия. Так, при автоматическом поиске учитывались в том числе и случаи употребления БиГ в значении аббревиатуры от Боснии и Герцеговины. Таким образом, перекодированная с английского языка лексема биг используется в российской прессе за период с 2000 по 2019 г. 567 раз (т. е. в среднем около 30 раз в год).

Значительную долю словоупотреблений (37 \%) составляют имена собственные. Так, биг встречается в названиях городов: Биг-Сур (вариант написания Биг-Сюр), Биг-Беар-Лэйк (штат Калифорния); компаний, например, «БИГ Девелопмент», «БИГ Реал Эстейт», а также в именах собственных: немецкая спортсменка Мартина Биг, звезда рок-н-ролла Биг Боппер, американский рестлер Пол Рэндалл Уайт, более известный под псевдонимом Биг Шоу и т. д.

Наиболее частотной в данной группе является лексема Биг Бен: на ее долю приходится почти 80 \% от всех топонимов и антропонимов. Следует отметить вариативность написания данного топонима: Биг-Бен, Биг Бэн или Биг Бен, хотя наиболее употребительной является, безусловно, последняя форма. Биг Беном в российской прессе называют как сами часы, так и знаменитую Лондонскую башню, на которой они расположены, о чем свидетельствуют приведенные ниже примеры:

«Кумир Дэвида - знаменитый фокусник Ури Геллер, остановивший однажды часы Биг Бен» [Комсомольская правда, 05.09.2003].

«Кстати, несколько ранее спецслужбы предупреждали о том, что “Аль-Каида” якобы готовится нанести удар по главному символу британской столицы - знаменитой башне Биг-Бен» [Труд-7, 29.08.2003].

Интересный факт: Биг Беном именуется не только один из наиболее известных символов Лондона, так называется и отечественная языковая школа, в которой изучают английский язык. В этой связи показательно отличное от общепринятого написание слова с открытым гласным в нижеследующем примере: «именно положительные отзывы о нашей работе привлекают в «Биг Бэн» все больше желающих изучать иностранный язык» [Труд-7, 01.07.2008].

По аналогии с приведенным топонимом в русском языке создаются и другие названия, например: частное предприятие «Биг-Крым» [Новый регион 2, 05.06.2008] или компания «Биг Новостройки» [lenta. $\mathrm{ru}, 20.08 .2015]$. Более того, перекодированное с английского языка слово заменяет русское прилагательное в словосочетании, близком по значению к «большая Москва»: «Киев: ограбленный платный туалет, барабаны с флагами, перекрывшие движение, лозунги: “Геть”, “Биг Москва, даешь Европу!”. Полицейские бьют демонстрантов. Демонстранты забрасывают камнями полицейских» [Новая газета, 28.08.2015].

Среди оставшегося массива словоупотреблений лексемы биг преобладают словосочетания, перекодированные с английского языка. Их показатели частотности (в порядке возрастания) представлены на рис. 1.

Таким образом, около половины всех словоупотреблений лексемы биг в современной российской прессе приходится на устойчивые словосочетания. Всего выявлено 11 сочетаний, характерных для английского языка, которые встречаются в перекодированном виде более двух раз. Наиболее употребительными являются биг мак и биг бэнд (встречаются около 50 раз и более). Характерно, что именно они зарегистрированы в «Новом словаре иностранных слов» [21], что подтверждает существование зависимости между частотой употребления иноязычного слова и вероятностью его фиксации в соответствующих словарях.

Интересные результаты были получены при сравнении показателей частотности употребления одних и тех же лексических единиц в иноязычной форме 


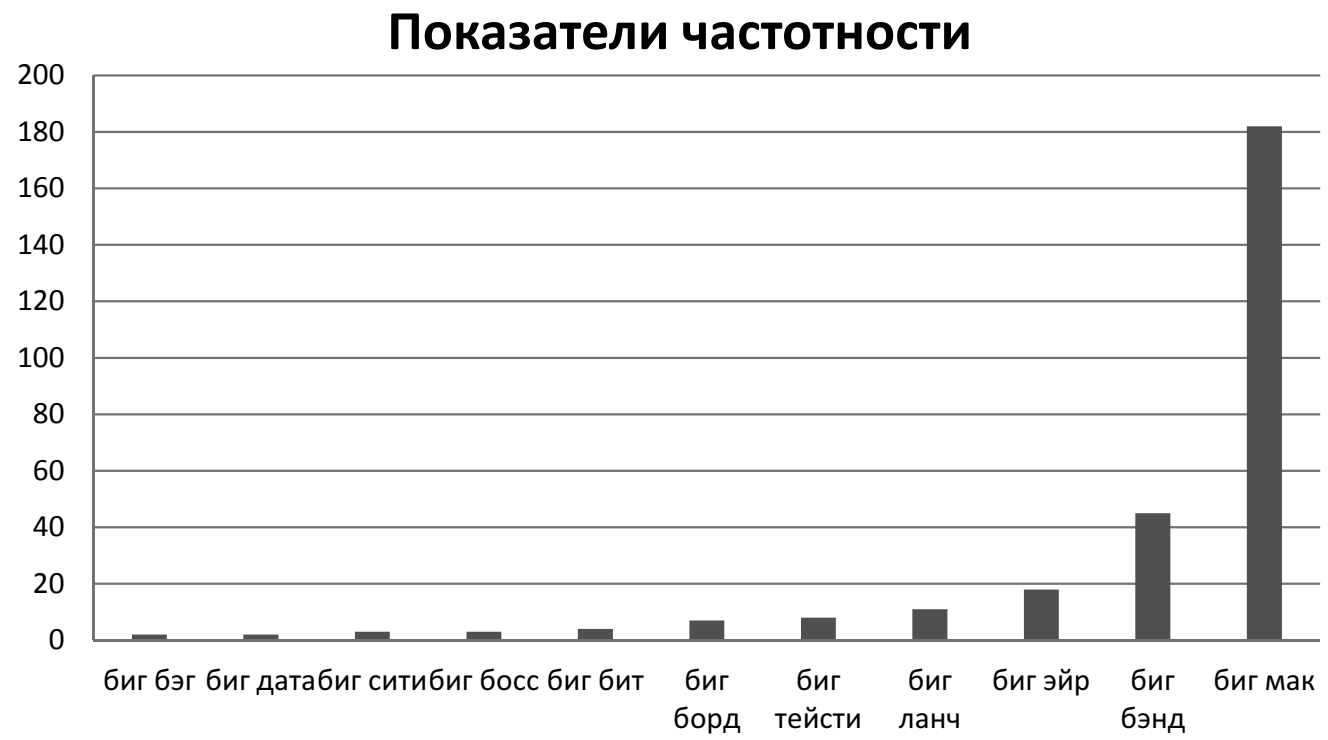

Puc. 1. Частотность словосочетаний с лексемой «биг»

(т. е. на латинице, в виде иноязычных вкраплений) и в перекодированном виде (т. е. на кириллице). Во-первых, практически все словосочетания встречаются в российской прессе в период с 2000 по 2019 г., как на английском, так и на русском языке, что подтверждает отсутствие резких границ между переключением кодов и межъязыковым перекодированием. Как минимум на начальной стадии вхождения иноязычное слово может употребляться параллельно как в форме иноязычного вкрапления, так и в перекодированном виде.

Во-вторых, если сравнить показатели частотности использования лексических единиц на латинице и кириллице, то можно выделить три группы. Для лексических единиц, зарегистрированных в словарях русского языка (биг мак, биг бэнд и биг эйр), харак- терна именно русскоязычная форма. В виде иноязычных вкраплений они используются лишь в единичных случаях, причем только в первое десятилетие анализируемого временного интервала. Другие лексемы, такие как биг дата и биг босс, используются преимущественно на латинице, что дает нам основания полагать, что они находятся лишь на начальном этапе вхождения. Первый уровень, который в данном случае подвергается освоению, - графический. И наконец, третью группу составляют лексемы, которые имеют приблизительно равные показатели частоты употребления как на латинице, так и на кириллице. Отметим, что данные словосочетания используются в современной прессе окказионально и имеют показатели частотности в пределах 2-5 словоупотреблений (рис. 2).

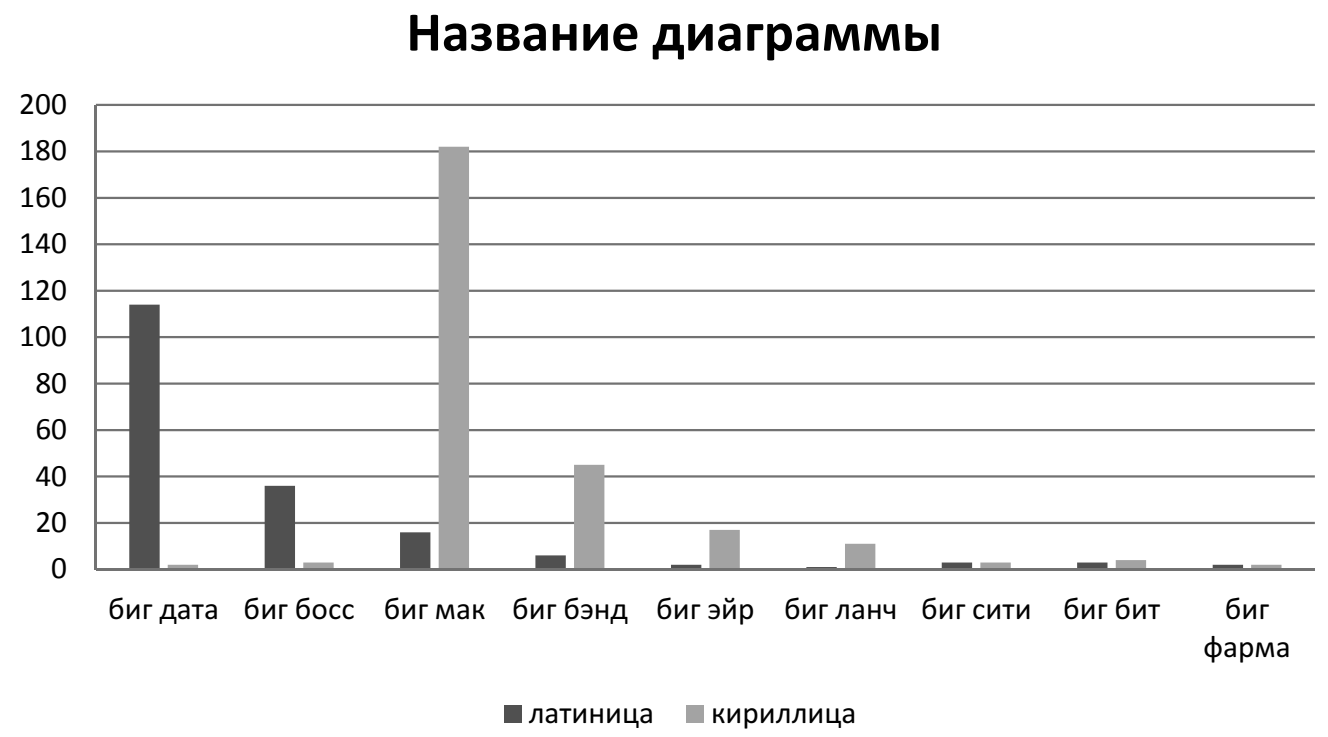

Puc. 2. Частотность употребления словосочетаний с помощью разных алфавитных основ 
Таким образом, в большинстве случаев лексема биг используется в российской прессе в составе перекодированного с английского языка словосочетания. При этом в ряде случаев оно воспринимается как сложное слово, образованное в результате сращения прилагательного и следующего за ним существительного, например: Биг-Мак, биг-эйр, биг-бэнд, биг-борд.

Следует отметить, что в русском языке перекодированные лексические единицы активно изменяются не только по числам, но и по падежам, несмотря на то, что в английском языке ни у прилагательных, ни у существительных нет падежных окончаний. В качестве иллюстрации приведем несколько примеров: «И вовсе не за Биг Маком» [Комсомольская правда, 27.03.2013], «кто будет покупать эти самые биг-маки?» [Московский комсомолец, 27.03.2016]; «никаких колбас, чипсов, чупа-чупсов, биг-маков» [Труд-7, 26.05.2006] и т. п.

Примечательно, что склоняются не только наиболее употребительные лексемы, которые по данным словарей уже вошли в состав русского языка, но и более редкие слова, например: «Однако в исключительных случаях можно обратиться к биг-боссу» [Труд-7, 07.09.2010].

Более того, выявлены случаи изменения и других грамматических категорий. В частности, можно привести пример субстантивации прилагательного биг в современной российской прессе: «В этом году на нее выйдут 30 конкурентов: 18 так называемых “бигов” (Big) - маститых, известных итальянских певцов и 12 молодых, начинающих исполнителей» [Известия, 27.02.2006].

Приведенные примеры со всей очевидностью свидетельствуют о том, что морфологическое освоение лексики иноязычного происхождения происходит еще до ее вхождения в систему принимающего языка. Как только слово начинает употребляться в речи, оно осознается как определенная часть речи и подчиняется нормам русского языка.

Обращает на себя внимание тот факт, что когда перекодированная лексика используется в перечислении, она буквально соседствует с другими англицизмами, образуя ряд иноязычных слов. Приведем несколько примеров:

«Все знают, что входят в нее продукты, не слишком полезные для здоровья: чипсы, шоколадки, булочки, биг-маки, попкорн, сосиски и сладкая газировка» [Труд-7, 19.10.2007].

«Для любителей прыжков - сноупарк: три биг-эй$p a$, хафпайп, три фанбокса, рейлы, в будний день там свободно... [Комсомольская правда, 21.11.2006].

«Была блузка "хлопчатобумажной” - превратилась в “коттоновую”, “встреча в верхах” стала “сам- митом", а привычное слово немецкого происхождения “бутерброд” заменено биг-маком» [РИА Новости, 02.04.2007].

В последнем примере особо подчеркивается иноязычное происхождение новомодных слов, хотя оно очевидно и в предыдущих контекстах. Другими словами, перекодированная лексика часто употребляется не изолированно, а образует целые синтагматические группы, выступая в качестве аттрактора других англицизмов.

Что касается лексического значения анализируемой лексемы, оно принципиально не меняется по сравнению с языком - источником заимствования. Однако это не мешает журналистам использовать иноязычное слово в стилистических целях, как средство создания дополнительной выразительности. Чаще всего употребление лексемы биг лежит в основе языковой игры. Так, например, конструктора космических систем Владимира Сыромятникова «иногда в шутку называют “Биг Чиз” (большой Сыр), намекая на его фамилию» [Труд-7, 14.04.2004].

На созвучии английского 'Мас' и русского 'маг' строится языковая игра в нижеследующем примере, где Дэвида Копперфилда называют большим магом и чародеем: «Биг-маг и чародей Дэвид Копперфилд предупреждает организаторов гастролей, чтобы в его гостиничном номере не было ничего, абсолютно!» [Комсомольская правда, 26.03.2004].

В другой статье употребление перекодированного с английского языка сочетания Биг мак, благодаря межъязыковой омонимии, создает аллюзию на дикий мак, выращиваемый в качестве сырья для производства наркотических средств. Статья, посвященная борьбе с оборотом наркотиков и ситуации в Афганистане так и называется - «Дикий Биг мак»: «2 июня в “Известиях" под заголовком “Дикий Биг мак” было опубликовано интервью с заместителем директора Федеральной службы Российской Федерации по контролю за оборотом наркотиков (ФСКН) - руководителем аппарата Государственного антинаркотического комитета Николаем Цветковым» [Известия, 09.06.2010].

\section{Выводы}

Обобщая наблюдения над особенностями функционирования лексемы биг в современной российской прессе, можно сделать следующие выводы:

- процесс вхождения иноязычного слова в русский язык является сложным и длительным, он занимает, как правило, ни одно десятилетие и включает в себя несколько этапов;

- освоение иноязычного слова в системе принимающего языка осуществляется постепенно, в несколько этапов; 
- для начальной стадии употребления иноязычного слова в речи характерна вариативность, причем речь идет как о возможности его написания с использованием алфавитной основы двух языков (языка-источника и языка-приемника), так и о существовании вариантов графического или фонетического оформления в процессе межъязыкового перекодирования;

- грамматическое освоение лексики иноязычного происхождения происходит практически одновременно с графическим освоением, причем независимо от фиксации в словарях иностранных слов или признания факта вхождения в состав лексической системы русского языка;

- на первом этапе межъязыкового перекодирования лексическое значение иноязычного слова не изменяется, копируя язык-источник заимствования;

- перекодированная с иностранного языка лексика используется в современной российской прессе в стилистических целях, как средство создания особой выразительности публицистических текстов.

В заключение хотелось бы подчеркнуть, что предложенный нами подход представляется продуктивным, поскольку позволяет, с одной стороны, отойти от традиционных дебатов по поводу понимания термина «заимствование», а с другой - рассматривать процесс заимствования лексики иноязычного происхождения в его развитии, в исторической перспективе. Безусловно, для того чтобы делать окончательные и более серьезные выводы, необходимо провести более масштабное исследование, которое позволит обобщить наблюдения над особенностями функционирования лексики иноязычного происхождения на разных этапах ее освоения. Однако тот эмпирический материал, который имеется в нашем распоряжении, вполне согласуется с высказанной точкой зрения.

\section{ЛИТЕРАТУРА}

1. Smokotin V. M., Alekseyenko A. S., Petrova G. I. The Phenomenon of Linguistic Globalization : English as the Global Lingua Franca // Social and Behavioral Sciences. 23 October 2014. Vol. 154. Pp. 509-513.

2. Болышева H. Н. Развитие языка в условиях глобализации (социально-философский аспект) : автореф. дис... канд. филос. наук. Красноярск, 2006. 24 с.

3. Подстрахова А. В. Англоязычная экспансия в европейские языки и проблема перевода // WEB журнал. Вып. 5. URL: http://vfnglu.wladimir.ru/Rus/NetMag/v5/ v5 ar02.htm

4. Gorlach M. A Dictionary of European Anglicisms : A Usage Dictionary of Anglicisms in Sixteen European Languages. Oxford University Press, 2005. 379 p.
5. Eryiğit G., Yirmibeşoğlu Z. Detecting Code-Switching between Turkish-English language pair // Proceedings of the 2018 EMNLP Workshop W-NUT : the 4th Workshop on Noisy User-generated Text. Brussels, 2018. Pp. 110-115.

6. Nkechi M. C. Linguistic Diversity, Code-switching and Language Shift in Nigeria // Journal of Siberian Federal University. Humanities \& Social Sciences. 2014. № 7. Pp. 381-393.

7. Кулешова Н. А. Англицизмы в испанских женских журналах // Вестник Рос. ун-та дружбы народов. Сер.: Лингвистика. 2010. № 2. С. 34-41.

8. Мокрушина Н. Ю. Англицизмы во французском языке как следствие процесса глобализации // Филологические науки. Вопросы теории и практики. 2014. № 6-1 (36). C. 127-129.

9. Шатилова Л. М. Стилистические функции англицизмов в немецкой и русской прессе // Филологические науки. Вопросы теории и практики. 2017. № 6-3 (72). С. $175-179$.

10. Аксенова А. T. Семантико-стилистическая адаптация новейшей иноязычной лексики (на материале СМИ) // Вестник РУДН. Сер.: Русский и иностранные языки и методика их преподавания. 2009. № 2. C. 22-29.

11. Myers-Scotton C. Code-Switching with English : Types of switching, types of communities // World Englishes. 1989. № 8. Pp. 333-346.

12. Poplack $S$. The English history of Afro-American English. Oxford : Blackwell Publishers, 2000. 158 p.

13. Muysken P. Bilingual Speech : A Typology of Code-Mixing. Cambridge, Cambridge University Press. 2000. $306 \mathrm{p}$.

14. Крысин Л. П. Лексическое заимствование и калькирование в русском языке последних десятилетий // Вопросы языкознания. 2002. №6. С. 27-36.

15. Проценко $E$. A. Смешение кодов как отражение глобализации межкультурной коммуникации. LAP LAMBERT Academic Publishing, 2015. 155 c.

16. Кретов А. А. Основы лексико-семантической прогностики. Воронеж: Воронежский государственный университет, 2006. $390 \mathrm{c}$.

17. Проиенко Е. А. Межъязыковое перекодирование как способ освоения иноязычной лексики в СМИ // Вестник Воронеж. гос. ун-та. Сер.: Лингвистика и межкультурная коммуникация. 2019. № 3. С. 3-10.

18. Камалетдинова А. Б. Иноязычная лексика в современных средствах массовой коммуникации : 1996-2001 гг. : автореф. дис. ... канд. филол. наук. Уфа, 2002. $12 \mathrm{c}$.

19. Буряковская В. А. Иноязычная лексика как стилистическая черта массмедиа // Стилистика сегодня и завтра : материалы IV Междунар. конф. М., 2016. C. $105-108$. 
20. Национальный корпус русского языка. URL: http://www.ruscorpora.ru/

21. Новый словарь иностранных слов : 25000 слов и словосочетаний / Захаренко Е. Н., Комарова Л. Н., Нечаева И. В. М. : Азбуковник, 2003. URL: http://slovari. $\mathrm{ru} /$ default.aspx $? \mathrm{~s}=0 \& \mathrm{p}=232$

\section{REFERENCES}

1. Smokotin V. M., Alekseyenko A. S., Petrova G. I. The Phenomenon of Linguistic Globalization: English as the Global Lingua Franca. Social and Behavioral Sciences. 2014. Vol. 154. Pp. 509-513.

2. Bolysheva N. N. Razvitie yazyka v usloviyakh globalizatsii (sotsial'no-filosofskij aspekt) [Language evolution in the context of globalization (social and philosophic aspects]. Dissertation abstract. Krasnoyarsk, 2006. 24 p.

3. Podstrakhova A. V. Angloyazychnaya ehkspansiya $v$ evropejskie yazyki i problema perevoda [English expansion in European languages and the problem of translation]. In: WEB journal. Vol. 5. Available at: http://vfnglu.wladimir. ru/Rus/NetMag/v5/v5_ar02.htm

4. Gorlach M. A Dictionary of European Anglicisms: A Usage Dictionary of Anglicisms in Sixteen European Languages. Oxford University Press, 2005. 379 p.

5. Eryiğit G., Yirmibeşoğlu Z. Detecting Code-Switching between Turkish-English language pair. In: Proceedings of the 2018 EMNLP Workshop W-NUT: the 4th Workshop on Noisy User-generated Text. Brussels, 2018. Pp. 110-115.

6. Nkechi M. C. Linguistic Diversity, Code-switching and Language Shift in Nigeria. In: Journal of Siberian Federal University. Humanities \& Social Sciences. 2014. No. 7. Pp. 381-393.

7. Kuleshova N. A. Anglitsizmy v ispanskikh zhenskikh zhurnalakh [Anglicisms in Spanish magazines for women]. In: Vestnik Rossijskogo universiteta druzhby narodov. Seriya: Lingvistika. 2010. No. 2. Pp. 34-41.

8. Mokrushina N. YU. Anglitsizmy vo frantsuzskom yazyke kak sledstvie protsessa globalizatsii [Anglicisms in French as a consequence of globalization process]. In: Filologicheskie nauki. Voprosy teorii i praktiki. 2014. No. 6-1 (36). Pp. 127-129.

9. SHatilova L. M. Stilisticheskie funktsii anglitsizmov $\mathrm{v}$ nemetskoj i russkoj presse [Stylistic functions of anglicisms in German and Russian press]. In: Filologicheskie nauki. Voprosy teorii i praktiki. 2017. No. 6-3 (72). Pp. 175179.

Воронежский институт МВД России

Проченко Е. А., кандидат филологических наук, доиент, доцент кафедры иностранных языков

E-mail:procatherine@mail.ru
10. Aksenova A. T. Semantiko-stilisticheskaya adaptatsiya novejshej inoyazychnoj leksiki (na materiale SMI) [Semantic and stylistic adaptation of the newest foreign words (a case study of mass media)]. In: Vestnik RUDN. Seriya Russkij i inostrannye yazyki i metodika ikh prepodavaniya. 2009. No. 2. Pp. 22-29.

11. Myers-Scotton C. Code-Switching with English: Types of switching, types of communities. In: World Englishes. 1989. No. 8. Pp. 333-346.

12. Poplack S. The English history of Afro-American English. Oxford: Blackwell Publishers, 2000. 158 p.

13. Muysken P. Bilingual Speech: A Typology of CodeMixing. Cambridge, Cambridge University Press. 2000. $306 \mathrm{p}$.

14. Krysin L. P. Leksicheskoe zaimstvovanie $i$ kal'kirovanie $v$ russkom yazyke poslednikh desyatiletij [Lexical borrowing and loan translation in the Russian language during last decades]. In: Voprosy yazykoznaniya. 2002. No. 6. P. 27-36.

15. Protsenko E. A. Smeshenie kodov kak otrazhenie globalizatsii mezhkul'turnoj kommunikatsii [Code mixing as a reflection of linguistic globalization]. LAP LAMBERT Academic Publishing, 2015. 155 p.

16. Kretov A. A. Osnovy leksiko-semanticheskoj prognostiki [Basis of lexico-semantic prognostics]. Voronezh, 2006. 390 p.

17. Protsenko E. A. Mezh"yazykovoe perekodirovanie kak sposob osvoeniya inoyazychnoj leksiki v SMI [Cross-language recoding as a way of foreign words' assimilation]. In: Vestnik VGU. Seriya: Lingvistika i mezhkul'turnaya kommunikatsiya. 2019. No. 3. Pp. 3-10.

18. Kamaletdinova A. B. Inoyazychnaya leksika v sovremennykh sredstvakh massovoj kommunikatsii: 1996$2001 \mathrm{gg}$. [Foreign words in the modern communication media: 1996-2001gg]. Dissertation abstract. Ufa, 2002. $12 \mathrm{p}$.

19. Buryakovskaya V. A. Inoyazychnaya leksika kak stilisticheskaya cherta massmedia [Foreign words as mass media stylistic feature]. In: Stilistika segodnya i zavtra: Materialy IV mezhdunarodnoj konferentsii. M., 2016. Pp. 105-108.

20. Natsional'nyj korpus russkogo yazyka [National Corpus of Russian Language]. Available at: http://www. ruscorpora.ru/

21. Novyj slovar' inostrannykh slov: 25000 slov i slovosochetanij [New dictionary of foreign words]. By: Zakharenko E. N., Komarova L. N., Nechaeva I. V. M.: Azbukovnik, 2003. Available at: http://slovari.ru/default.aspx?s=0\&p=232

Voronezh Institute of the Ministry of the Interior of Russia Protsenko E. A., Candidate of Philology, Associate Professor of Foreign Languages Department

E-mail: procatherine@mail.ru 
Поступила в редакцию 6 ноября 2020 г.

Принята к публикации 29 декабря 2020 г.

\section{Для цитирования:}

Процеенко E. А. Биг мак, или траектория одного англицизма в современной прессе // Вестник Воронежского государственного университета. Серия: Лингвистика и межкультурная коммуникация. 2021. № 1. С. 115-122. DOI: https://doi.org/10.17308/lic.2021.1/3245
Received: 6 November 2020

Accepted: 29 December 2020

\section{For citation:}

Protsenko E. A. Big Mac or a pathway of one anglicism in modern press. Proceedings of Voronezh State University. Series: Linguistics and Intercultural Communication. 2021. No. 1. Pp. 115-122. DOI: https://doi.org/10.17308/ lic. $2021.1 / 3245$ 